\title{
Ultimate lateral load of slope-stabilising piles
}

\author{
R. DI LAORA*, R. M. S. MAIORANO† and S. AVERSA $\dagger$
}

\begin{abstract}
The paper deals with the design and analysis of slope-stabilising piles and adopts limit equilibrium concepts to derive pile contribution to stability. Analytical expressions for pile ultimate load are derived in terms of the force and the moment to be used in routine slope-stability analyses to take into account pile contribution. Free and head-restrained isolated piles, with infinite and finite section capacity, in drained and undrained conditions are considered.
\end{abstract}

KEYWORDS: limit equilibrium methods; piles \& piling; slopes

ICE Publishing: all rights reserved

\section{NOTATION}

A, B, C failure mechanisms for infinite pile sectional strength

B1, BY, B2 failure mechanisms involving plastic hinging

$d$ pile diameter

$k_{\mathrm{d} 1}, k_{\mathrm{d} 2}$ bearing capacity factors in drained conditions for sliding and firm soil

$k_{\mathrm{p} 1}, k_{\mathrm{p} 2}$ passive earth pressure coefficients for sliding and firm soil

$k_{\mathrm{u} 1}, k_{\mathrm{u} 2}$ bearing capacity factors in undrained conditions for sliding and firm soil

$L$ pile length

$l_{1}$ length of the portion of the pile embedded in the sliding soil

$l_{2}$ length of the portion of the pile embedded in the firm soil

$M_{\mathrm{y}}$ pile sectional yielding moment

$m_{\mathrm{d}}$ dimensionless pile yielding moment in drained conditions

$m_{\mathrm{d}, \lim }$ limit dimensionless pile yielding moment for free-head piles in drained conditions

$m_{\mathrm{d}, \mathrm{lim}, \mathrm{r}}$ limit dimensionless pile yielding moment for fixed-head piles in drained conditions

$m_{\mathrm{u}} \quad$ dimensionless pile yielding moment in undrained conditions

$m_{\mathrm{u}, \mathrm{lim}}$ limit dimensionless pile yielding moment for free-head piles in undrained conditions

$m_{\mathrm{u}, \mathrm{lim}, \mathrm{r}}$ limit dimensionless pile yielding moment for fixed-head piles in undrained conditions

$m_{\mathrm{u}}^{*} \quad$ dimensionless pile yielding moment separating mechanisms B1 and BY in undrained conditions

$s_{\mathrm{u} 1} \quad$ undrained shear strength of the sliding soil

$s_{\mathrm{w} 2} \quad$ undrained shear strength of the firm soil

$T_{i}, M_{i}$ stabilising force and moment with respect to slip surface for mechanism $i$

$t_{\mathrm{d}}$ dimensionless stabilising force in drained conditions

$t_{\mathrm{d} i}$ dimensionless stabilising force in drained conditions for mechanism $i$

$t_{\mathrm{u}}$ dimensionless stabilising force in undrained conditions

$t_{\mathrm{u} i}$ dimensionless stabilising force in undrained conditions for mechanism $i$

$t_{\mathrm{u}}^{*} \quad$ dimensionless stabilising force separating mechanisms B1 and BY in undrained conditions

$\alpha$ slope inclination

$\gamma$ soil unit weight

Manuscript received 26 April 2017; first decision 13 June 2017; accepted 29 June 2017.

Published online at www.geotechniqueletters.com on 31 July 2017.

*Department of Engineering, University of Napoli Parthenope, Napoli, Italy (Orcid:0000-0002-9993-5353).

$\dagger$ Department of Engineering, University of Napoli Parthenope, Napoli, Italy.

\author{
$\lambda$ dimensionless pile embedment $\left(=l_{2} / l_{1}\right)$ \\ $\lambda_{\lim }$ limit dimensionless pile embedment for \\ free-head piles \\ $\lambda_{\text {lim,r }}$ limit dimensionless pile embedment for \\ fixed-head piles \\ $\lambda^{*} \quad$ dimensionless pile embedment separating \\ mechanisms B1 and BY in undrained conditions \\ $\chi_{\mathrm{u}}, \chi_{\mathrm{d}}$ strength ratios between sliding and firm soil in \\ undrained and drained conditions
}

\section{INTRODUCTION}

The use of piles for stabilising unstable slopes or for increasing the safety conditions of a precarious slope is a popular technique reported as successful in a number of works since the 1970s (Ito \& Matsui, 1975; Fukuoka, 1977; Sommer, 1977). Despite the reliability, effectiveness and success of such a technique, the design of slope-stabilising piles still presents a number of obscure points, and a unique, widely accepted procedure for routine design has not been developed. A common approach is that proposed by Viggiani (1981) which involves three steps: $(a)$ evaluation of the shear force required to increase the stability of the precarious slope up to a desired amount; $(b)$ evaluation of the shear force contribution that piles can offer to transfer forces from the unstable to the stable ground; $(c)$ from comparison of calculations in $(a)$ and $(b)$, establish the type, number and the location of piles. In the framework of Modern Geotechnical Codes, this method is suitable for the ultimate limit state conditions, whereas the serviceability conditions, intended to evaluate the admissibility of displacements, must be necessarily tackled by more complex numerical analyses involving pile-soil interaction. Step (a) may be achieved by conventional slope-stability analyses on the basis of a limit equilibrium approach and thus computing the required additional resisting force needed to increase the safety factor up to the target value. Many contributions dealt with the evaluation of the stabilising contribution offered by isolated or rows of piles (step $b$ ). Analytical solutions were offered by Ito \& Matsui (1975), De Beer \& Carpentier (1977) and Viggiani (1981). The latter provided solutions for a single free-head pile embedded in fine-grained soil in undrained conditions (total stress analysis) in the framework of the limit equilibrium method. With a similar approach, Muraro et al. (2014) have obtained the solution for the case of a rigid (not yielding) single free-head pile in drained conditions. Ito \& Matsui (1975) studied the pile reaction forces when the soil is forced to squeeze between two infinitely long piles, providing two expressions obtained by using either the theory of plastic deformation or the theory of plastic flow. De Beer \& Carpentier (1977) offered improved equations, by overcoming some limitations due to the 
strong hypotheses involved in the derivation of the previous methods. A number of contributions dealt with pile-soil interaction, by means of Winkler approach (e.g. Baguelin et al., 1977; Fukuoka, 1977; Guo, 2006) or continuum models (e.g. Poulos, 1973, 1995, 1999; Hull, 1993). Finally, in some studies numerical analyses by way of the finite-difference or finite-element method are performed (Ito et al., 1979; Oakland \& Chameau, 1984; Poulos \& Chen, 1997; Kourkoulis et al., 2011, 2012). Regarding step (c), different works dealt with the optimal position of piles along the slope (Lee et al., 1995; Hassiotis et al., 1997; Cai \& Ugai, 2000; Ausilio et al., 2001; Pan et al., 2012). Regarding pile spacing, Smethurst \& Powrie

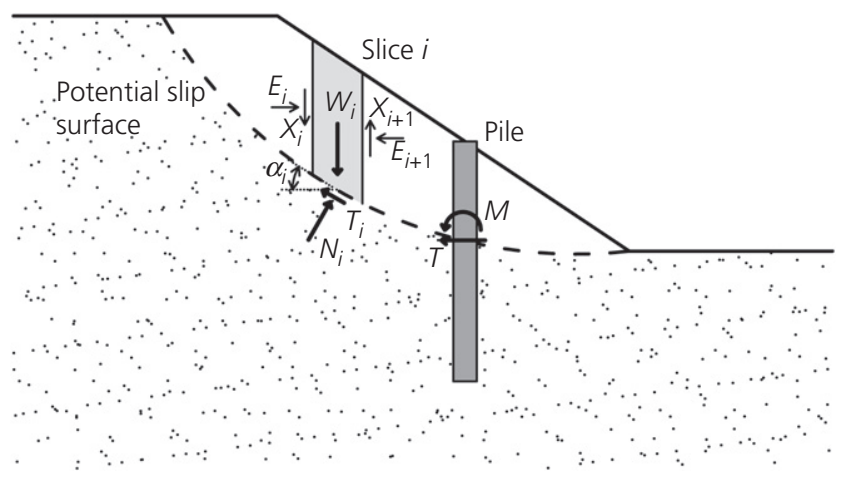

Fig. 1. Problem under consideration: assessment of pile contribution in the realm of limit equilibrium stability analyses of reinforced slopes

$\begin{array}{ccc}\text { Soil } & \text { Shear Bending } \\ \text { reaction } & \text { force } & \text { moment }\end{array}$
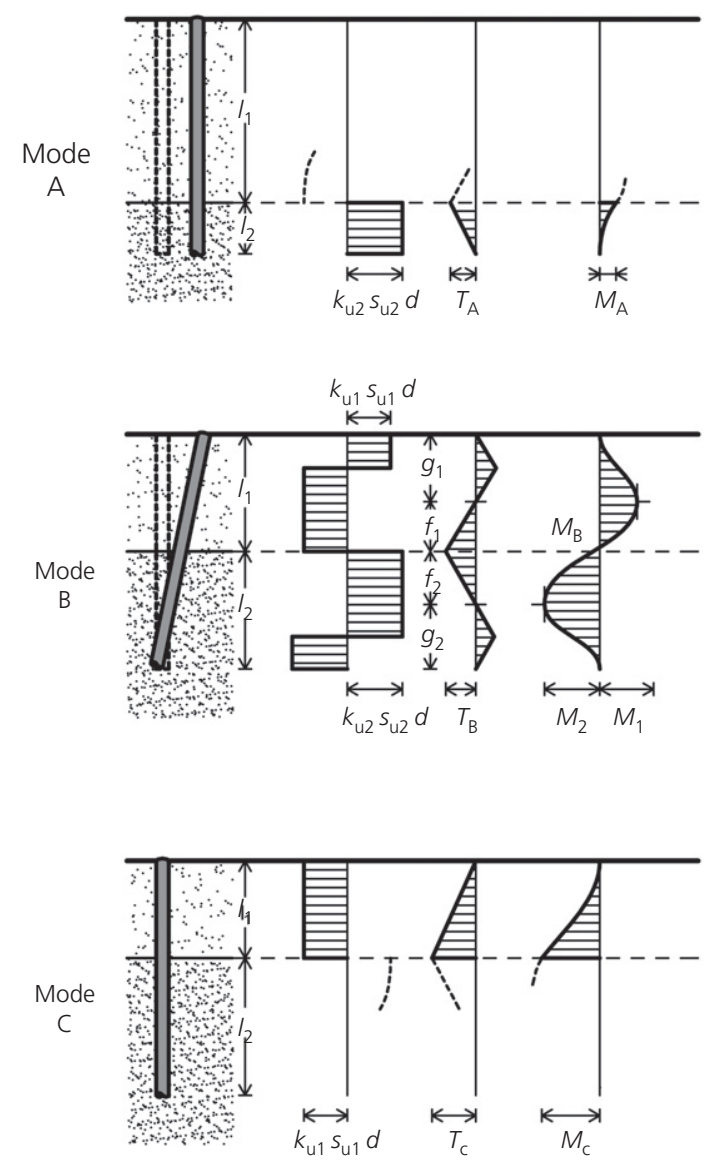

(2007) and Kourkoulis et al. (2011) have highlighted how a spacing of four pile diameters represents a general trend in engineering practice as it optimises the benefit/cost ratio.

A relevant limitation of the traditional approach is that the calculation of the piles' contribution to stability refers to the critical slip surface (i.e. the one possessing the least safety factors) for the unreinforced slope. However, the presence of the piles changes the stability conditions and the critical slip surface may even not intersect piles for very close transversal spacing among the reinforcement elements. Assuming that the safety factor of the reinforced slope is the improved safety factor of the slip surface which was the critical one in the absence of reinforcement is a very coarse approximation that may lead to a severely unconservative design.

To overcome this limitation, one could take into account the pile contribution directly in the stability analysis, for every slip surface under consideration (Fig. 1), by means of a force and a moment representing the ultimate pile-soil contact pressures. Such an approach is feasible only if ready-to-use analytical expressions are available for ultimate pile load. The scope of this work is therefore to propose a comprehensive set of analytical solutions for single piles, both free and fixed against rotation at the top, for drained and undrained conditions, as reported in the following. Group/arching effects are thereby not covered in this work.

\section{ULTIMATE PILE LOAD IN UNDRAINED CONDITIONS}

Viggiani (1981) has derived analytical expressions for the ultimate load of a free-head single rigid-plastic pile of diameter $d$
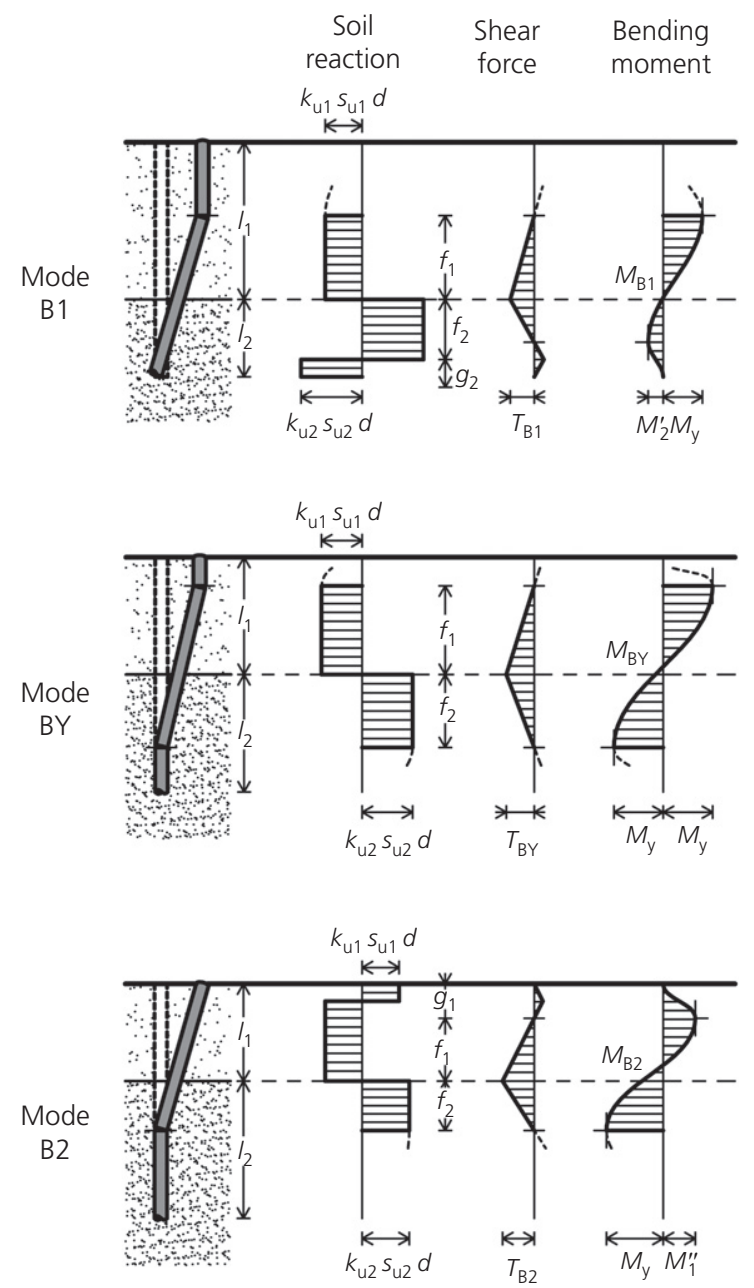

Fig. 2. Failure mechanisms and associated distribution of soil reaction, shear force and bending moment in undrained conditions and total stress analysis (modified from Viggiani, 1981) 
and length $L$, crossing an unstable horizontal layer of thickness $l_{1}$ subjected to uniform horizontal displacement, and penetrating the underlying stable soil for a length $l_{2}$, both modelled as rigid-plastic purely cohesive materials. Thereby, such a formulation is suitable for treating undrained conditions through a total stress analysis in fine-grained soils where the upper and lower layers have undrained shear strengths equal to $s_{\mathrm{u} 1}$ and $s_{\mathrm{u} 2}$, respectively. Viggiani (1981) followed a limit equilibrium approach, similar to that proposed by Broms (1964a) for piles loaded by transverse loads applied at their upper end, and identified six possible failure mechanisms, corresponding to a stiff pile having infinite (mechanisms A, B, C) and finite (mechanisms B1, BY, B2) yielding moment $M_{\mathrm{y}}$ of the cross-section (Fig. 2). More specifically, mode A occurs when the embedment in the stable layer is small, so that the sliding soil carries the pile and the latter fully mobilises soil strength in the stable layer. Limited contribution to stability is obtained by the insertion of piles. Mode C, also referred as 'flow mode', occurs for a large embedment and the unstable soil fails around the pile. Maximum contribution is expected from the pile to stabilise the slope. In between the above mechanisms, an intermediate mode B is found, where the soil strength is fully mobilised everywhere. When bending moments reach the yielding moment in a certain pile section, plastic hinging occurs and modes B1, BY and B2 are possible. It is convenient to define the dimensionless quantities

$$
\begin{aligned}
& \chi_{\mathrm{u}}=\frac{k_{\mathrm{u} 1} s_{\mathrm{u} 1}}{k_{\mathrm{u} 2} s_{\mathrm{u} 2}} \\
& \lambda=\frac{l_{2}}{l_{1}} \\
& m_{\mathrm{u}}=\frac{M_{\mathrm{y}}}{k_{\mathrm{u} 1} s_{\mathrm{u} 1} d l_{1}^{2}} \\
& t_{\mathrm{u}}=\frac{T}{k_{\mathrm{u} 1} s_{\mathrm{u} 1} d l_{1}}
\end{aligned}
$$

\begin{tabular}{|c|c|}
\hline Mode A & $\begin{array}{l}t_{\mathrm{uA}}=\frac{T_{\mathrm{A}}}{k_{\mathrm{u} 1} s_{\mathrm{u} 1} d l_{1}}=\frac{\lambda}{\chi_{\mathrm{u}}}(2 \mathrm{a}) \\
\frac{M_{\mathrm{A}}}{k_{\mathrm{u} 1} s_{\mathrm{u} 1} d l_{1}^{2}}=\frac{\lambda}{2} \frac{T_{\mathrm{A}}}{k_{\mathrm{u} 1} s_{\mathrm{u} 1} d l_{1}}=-\frac{\lambda}{2} t_{\mathrm{uA}}(2 \mathrm{~b})\end{array}$ \\
\hline Mode B* & $\begin{array}{l}t_{\mathrm{uB}}=\frac{T_{\mathrm{B}}}{k_{\mathrm{u} 1} s_{\mathrm{u} 1} d l_{1}}=\sqrt{\frac{(1+\lambda)^{2}}{\left(1+\chi_{\mathrm{u}}\right)^{2}}+\frac{\left(\chi_{\mathrm{u}}+\lambda^{2}\right)}{\chi_{\mathrm{u}}\left(1+\chi_{\mathrm{u}}\right)}}-\frac{(1+\lambda)}{\left(1+\chi_{\mathrm{u}}\right)}(3 \mathrm{a}) \\
\frac{M_{1}}{k_{\mathrm{u} 1} s_{\mathrm{u} 1} d l_{1}^{2}}=\frac{\left(1-t_{\mathrm{uB}}\right)^{2}}{4}(3 \mathrm{~b}) \\
\frac{M_{2}}{k_{\mathrm{u} 1} s_{\mathrm{u} 1} d l_{1}^{2}}=\frac{\left(\lambda-\chi_{\mathrm{u}} t_{\mathrm{uB}}\right)^{2}}{4 \chi_{\mathrm{u}}}(3 \mathrm{c}) \\
\frac{M_{\mathrm{B}}}{k_{\mathrm{u} 1} s_{\mathrm{u} 1} d l_{1}^{2}}=\frac{\left(\lambda-\chi_{\mathrm{u}}\right)\left(\lambda+\chi_{\mathrm{u}}\left(3+\chi_{\mathrm{u}}+3 \lambda\right)-2 \sqrt{\chi_{\mathrm{u}}\left(\chi_{\mathrm{u}}^{2}+\lambda^{2}+2 \chi_{\mathrm{u}}\left(1+\lambda+\lambda^{2}\right)\right)}\right)}{4 \chi_{\mathrm{u}}\left(1+\chi_{\mathrm{u}}\right)^{2}}\end{array}$ \\
\hline Mode C & $\begin{array}{l}t_{\mathrm{uC}}=\frac{T_{\mathrm{C}}}{k_{\mathrm{u} 1} s_{\mathrm{u} 1} d l_{1}}=1 \text { (4a) } \\
\frac{M_{\mathrm{C}}}{k_{\mathrm{u} 1} s_{\mathrm{u} 1} d l_{1}^{2}}=\frac{1}{2}(4 \mathrm{~b})\end{array}$ \\
\hline Mode B1† & $\begin{array}{l}t_{\mathrm{uB} 1}=\frac{T_{\mathrm{B} 1}}{k_{\mathrm{u} 1} s_{\mathrm{u} 1} d l_{1}}=\frac{\lambda}{\chi_{\mathrm{u}}+2}\left[\sqrt{\left.\frac{2 \chi_{\mathrm{u}}+2}{\chi_{\mathrm{u}}}+4 \frac{\chi_{\mathrm{u}}+2}{\lambda^{2}} m_{\mathrm{u}}-1\right]}(5 \mathrm{a})\right. \\
\frac{M_{2}^{\prime}}{k_{\mathrm{u} 1} s_{\mathrm{u} 1} d l_{1}^{2}}=\frac{1}{4 \chi_{\mathrm{u}}}\left(\lambda-\chi_{\mathrm{u}} t_{\mathrm{uB} 1}\right)^{2}(5 \mathrm{~b}) \\
\frac{M_{\mathrm{B} 1}}{k_{\mathrm{u} 1} s_{\mathrm{u} 1} d l_{1}^{2}}=\frac{\left(2+3 \chi_{\mathrm{u}}\right) \lambda^{2}-2 \chi_{\mathrm{u}}^{2}\left(2+\chi_{\mathrm{u}}\right) m_{\mathrm{u}}-2 \sqrt{2} \lambda \sqrt{\chi_{\mathrm{u}}\left(1+\chi_{\mathrm{u}}\right) \lambda^{2}+2 \chi_{\mathrm{u}} m_{\mathrm{u}}\left(2+\chi_{\mathrm{u}}\right)}}{2 \chi_{\mathrm{u}}\left(2+\chi_{\mathrm{u}}\right)^{2}}(5 \mathrm{c})\end{array}$ \\
\hline Mode BY & $\begin{array}{l}t_{\mathrm{uBY}}=\frac{T_{\mathrm{BY}}}{k_{\mathrm{u} 1} s_{\mathrm{u} 1} d l_{1}}=2 \sqrt{\frac{m_{\mathrm{u}}}{\left(1+\chi_{\mathrm{u}}\right)}}(6 \mathrm{a}) \\
\frac{M_{\mathrm{BY}}}{k_{\mathrm{u} 1} s_{\mathrm{u} 1} d l_{1}^{2}}=m_{\mathrm{u}} \frac{1-\chi_{\mathrm{u}}}{1+\chi_{\mathrm{u}}}(6 \mathrm{~b})\end{array}$ \\
\hline Mode B2 & $\begin{array}{l}t_{\mathrm{uB} 2}=\frac{T_{\mathrm{B} 2}}{k_{\mathrm{u} 1} s_{\mathrm{u} 1} d l_{1}}=\frac{\sqrt{1+\left(2 \chi_{\mathrm{u}}+1\right)\left(1+4 m_{\mathrm{u}}\right)}-1}{2 \chi_{\mathrm{u}}+1}(7 \mathrm{a}) \\
\frac{M_{1}^{\prime \prime}}{k_{\mathrm{u} 1} s_{\mathrm{u} 1} d l_{1}^{2}}=\frac{1}{4}\left(1-t_{\mathrm{uB} 2}\right)^{2}(7 \mathrm{~b}) \\
\frac{M_{\mathrm{B} 2}}{k_{\mathrm{u} 1} s_{\mathrm{u} 1} d l_{1}^{2}}=\frac{2 m_{\mathrm{u}}-\chi_{\mathrm{u}}\left(3+2 \chi_{\mathrm{u}}-4 m_{\mathrm{u}}\right)+2 \sqrt{2} \chi_{\mathrm{u}} \sqrt{1+\chi_{\mathrm{u}}+2 m_{\mathrm{u}}+4 \chi_{\mathrm{u}} m_{\mathrm{u}}}}{2\left(1+2 \chi_{\mathrm{u}}\right)^{2}}(7 \mathrm{c})\end{array}$ \\
\hline
\end{tabular}

where $k_{\mathrm{u} 1}$ and $k_{\mathrm{u} 2}$ are the bearing capacity factors (taken as 4 and 8, respectively, by Viggiani, 1981); $T$ is the shear force

Table 1. Shear force and bending moment offered by the pile for the six mechanisms (modified from Viggiani, 1981)

*In the original work there is an error in the expression equivalent to equation ( $3 \mathrm{c}$ ): the parameter $\chi$ (herein denoted as $\chi_{\mathrm{u}}$ ) multiplying the dimensionless shear force $t_{\mathrm{uB}}$ is omitted. The same correction has been reported by Chmoulian (2004)

$\dagger$ In the original work, there is a typographical error in the expression equivalent to equation (5a): parameter $\lambda$ instead of $\chi$ is reported in the denominator in the first term under the square root. The same correction has been reported by Chmoulian (2004) 
and $M_{\mathrm{y}}$ is the yielding moment. Dimensionless values of the reaction force and moment, with respect to the slip surface, offered by the pile for the six mechanisms may be obtained from equilibrium equations and are reported in Table 1. As an element of novelty over previous studies, the value of moment has been reported.

For a given soil and pile configuration, the minimum shear force at the level of the interface between the two layers among these mechanisms represents the contribution offered by the pile to stabilise the upper soil layer in Fig. 1.

It is evident that such a method is directly applicable when a clear slip surface may be identified as the separation between two layers with sharply differing strengths. However, the analytical solutions provided by the author may be used in routine stability analyses for curved slip surfaces (where the particular condition of no strength contrast between unstable and firm soil occurs) along with bending moments at the level of the slip surface derived in this work, reported in Table 1. Note that this moment is negative and of small magnitude for mode A while it is positive for mode $\mathrm{C}$. In the latter case, the resultant force is located above the interface and thereby represents an unfavourable contribution.

With the aim of further exploring the analytical results and their physical meaning, a schematic representation of all the different mechanisms in the plane $t_{\mathrm{u}}: \lambda$ is offered in Fig. 3. For any value of $m_{\mathrm{u}}$, the trend of dimensionless shear force $t_{\mathrm{u}}$ by varying $\lambda$ has three distinct zones. First, for small embedment ratios, a linear trend is observed (mechanism A), followed by a parabolic trend (mechanism B1 or B, depending on $m_{\mathrm{u}}$ ). For larger $\lambda$ the value of $t_{\mathrm{u}}$ is constant (mechanisms BY, B2 or C). Mechanisms B1 and BY are separated by a straight line having the equation

$$
\begin{aligned}
& t_{\mathrm{u}}=\frac{\lambda}{\chi_{\mathrm{u}}} \frac{1}{1+\sqrt{\chi_{\mathrm{u}}+1 / \chi_{\mathrm{u}}}}=\lambda\left(\sqrt{\frac{\chi_{\mathrm{u}}+1}{\chi_{\mathrm{u}}}}-1\right) \\
& \text { for } \lambda<\lambda^{*}
\end{aligned}
$$

the value of $\lambda^{*}$ being

$$
\lambda^{*}=\frac{\left(\sqrt{\chi_{\mathrm{u}}+1}-1\right)}{\chi_{\mathrm{u}}}
$$

For larger $\lambda$, the limit value $t_{\mathrm{u}}^{*}$ separates mechanisms BY and $\mathrm{B} 2$ and assumes the value

$$
\begin{aligned}
& t_{\mathrm{u}}^{*}=t_{\mathrm{u}}\left(\lambda^{*}\right)=\left(\frac{\sqrt{\chi_{\mathrm{u}}+1}-1}{\chi_{\mathrm{u}}}\right)\left(\sqrt{\frac{\chi_{\mathrm{u}}+1}{\chi_{\mathrm{u}}}}+1\right) \\
& \quad \text { for } \lambda>\lambda^{*}
\end{aligned}
$$

Failure according to mechanism BY or B2 depends on whether the dimensionless yielding moment $m_{\mathrm{u}}$ is lower or larger than a critical value $m_{\mathrm{u}}^{*}$, whose analytical expression is

$$
m_{\mathrm{u}}^{*}=\frac{1+\chi_{\mathrm{u}}}{2 \chi_{\mathrm{u}}^{2}}\left[\frac{\chi_{\mathrm{u}}+2}{2}-\sqrt{1+\chi_{\mathrm{u}}}\right]
$$

There is a threshold value of $\lambda$ beyond which the dimensionless shear force on the sliding plane is constant and equal to the maximum value $t_{\mathrm{u}}=1$. This is particularly interesting from a design viewpoint, because it indicates the minimum value of embedment length in the firm soil, for a fixed thickness of the unstable layer, to achieve the maximum shear force for a given section capacity. This limit value, $\lambda_{\lim }$, is obtained by intersecting mechanisms $\mathrm{B}$ and $\mathrm{C}$ as

$$
\lambda_{\lim }=\chi_{\mathrm{u}}+\sqrt{2 \chi_{\mathrm{u}}^{2}+2 \chi_{\mathrm{u}}}
$$

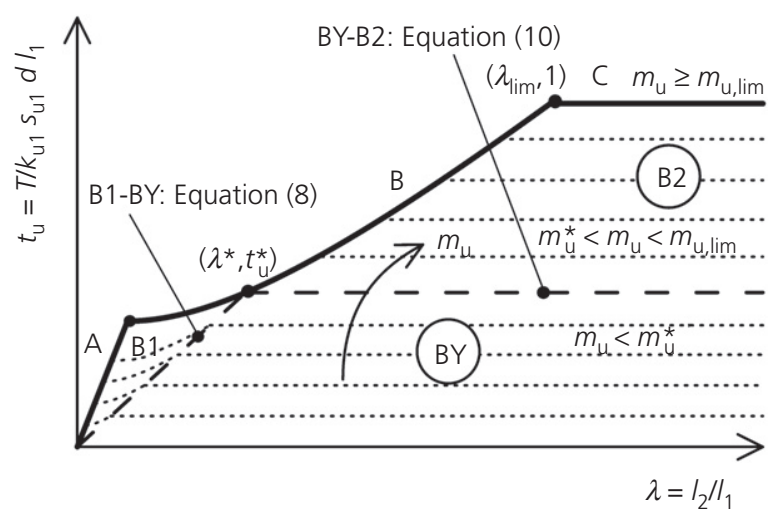

Fig. 3. Schematic representation of dimensionless shear force for a free-head pile in undrained conditions and associated failure mechanisms

The maximum shear force is obtained for mechanism $\mathrm{C}$ and for a particular condition occurring in mechanism B2 - that is, when the plastic hinge is located at the sliding plane $\left(f_{2}=0\right.$ and $g_{1}=0$ in Fig. 2) with a value of dimensionless section capacity

$$
m_{\mathrm{u}, \lim }=\frac{\chi_{\mathrm{u}}+1}{2}
$$

which thereby indicates the value of the yielding moment above which no benefit is obtained in terms of pile performance. For different values of strength ratios and bending sectional capacity, the normalised pile shear force at the interface is represented in Fig. 4.

With the aim of providing a more comprehensive set of ready-to-use expressions for pile contribution to slope stability, the following sections report an extension of Viggiani's (1981) solutions for head-restrained piles, in undrained and drained conditions.

\section{Piles with head restrained against rotation}

In engineering practice, it is not rare the use of two or more parallel rows of slope-stabilising piles connected at the top by stiff structural elements. In these conditions, modelling piles' heads as fixed against rotation may be a more suitable choice.

By inspecting Fig. 2, it is straightforward to notice that among the six mechanisms detected for free-head piles, B and B2 imply rotation at pile top and thus only mechanisms $A$ and $C$ (for infinitely resistant piles) and mechanisms B1 and BY (involving section yielding) are admissible for the kinematics of the problem under investigation. It can be proven, yet is not done here in the interest of space, that any mechanisms other than the ones considered previously are not admissible.

A schematic representation of the different mechanisms in the plane $t_{\mathrm{u}}-\lambda$ is offered in Fig. 5. The beneficial effect of the head restraint is evident for large values of sectional capacity: a pile that would fail with mechanism B under free-head conditions, due to the head fixity fails with mechanism $\mathrm{A}$ or $\mathrm{C}$, whereas piles associated to mechanism B2 turn to BY, increasing their ultimate load. On the contrary, for low values of sectional yielding capacity, no benefit is observed in terms of magnitude of the stabilising force as even for free-head piles a plastic hinge below the pile head would control pile failure.

Mechanisms B1 and BY are separated again from the line described by equation (8), up to a limit value of $\lambda$ equal to 


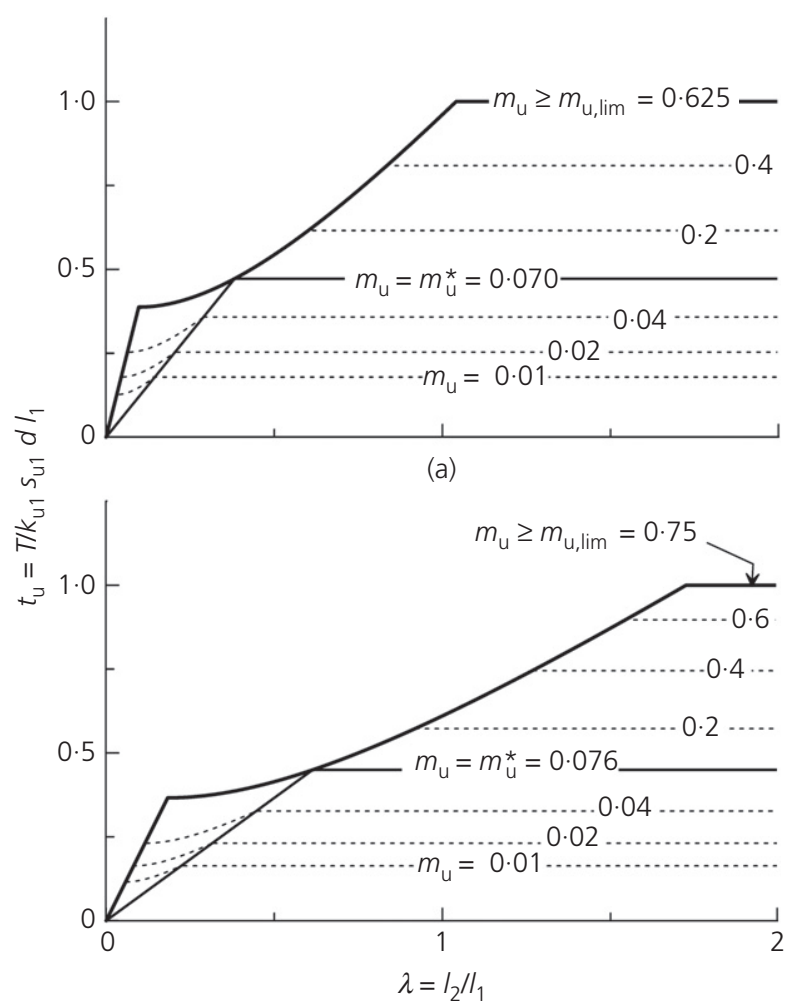

(b)

Fig. 4. Dimensionless shear force for free-head piles in undrained conditions for different values of dimensionless yielding moment and strength ratio of sliding and firm soil: (a) $\chi_{\mathrm{u}}=0.25$; (b) $\chi_{\mathrm{u}}=0.5$

$$
\lambda_{\lim , \mathrm{r}}=\frac{1}{\sqrt{\left(\chi_{\mathrm{u}}+1 / \chi_{\mathrm{u}}\right)}-1}=\chi_{\mathrm{u}}\left(\sqrt{\frac{\chi_{\mathrm{u}}+1}{\chi_{\mathrm{u}}}}+1\right)
$$

For $\lambda>\lambda_{\text {lim,r }}$ the maximum shear force is obtained for any value of $m>m_{\mathrm{u}, \mathrm{lim}, \mathrm{r}}$, the latter being equal to

$$
m_{\mathrm{u}, \lim , \mathrm{r}}=\frac{\chi_{\mathrm{u}}+1}{4}
$$

It can be noticed that this value is half of the one corresponding to the free-head case. Values of yielding moment larger than $m_{\mathrm{u}, \mathrm{lim}, \mathrm{r}}$ can be helpful in the mechanism $\mathrm{B} 1$, where the shear force increases for values of $m$ up to the corresponding limit values for free-head piles, for which mechanism B1 occurs in the conditions described by the point of intersection of A and C. Quantitative results for different values of strength ratios and dimensionless yielding moment are represented in Fig. 6. It is worth noting that for mechanism $\mathrm{C}$ the head moment is indeterminate and thereby the interface moment is unknown. However, in a design problem the optimum condition is represented by the point where mechanisms B1, BY and C coincide, where the moment at head is equal to the yielding moment for $m_{\mathrm{u}}=m_{\mathrm{u}, \lim }$.

\section{ULTIMATE PILE LOAD IN DRAINED CONDITIONS}

In this section, the ultimate pile load is derived for drained conditions. Calculations are carried out in the special case of dry cohesionless soil. Nevertheless, when the groundwater level is coincident with the free surface, all the results are still valid if the buoyant unit weight is utilised instead of the dry unit weight. It would be straightforward to extend the derivations to the case of generalised drained conditions (i.e. the soil possesses positive values of both effective

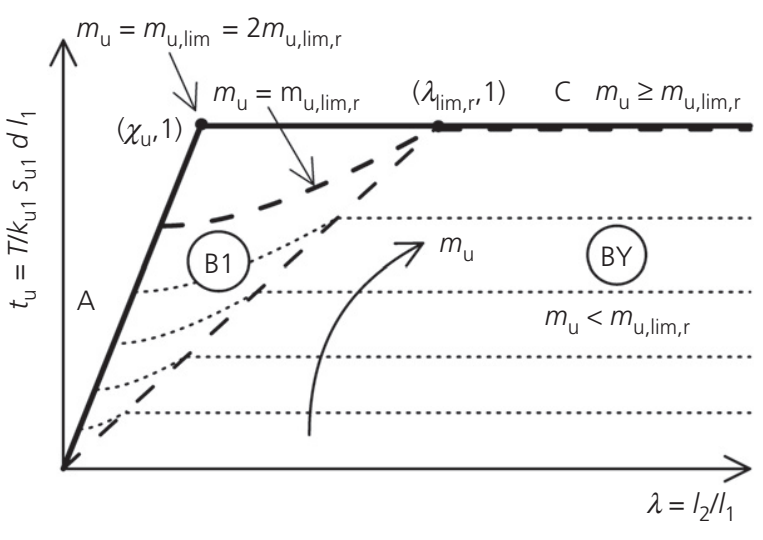

Fig. 5. Schematic representation of dimensionless shear force for a fixed-head pile in undrained conditions and associated failure mechanisms

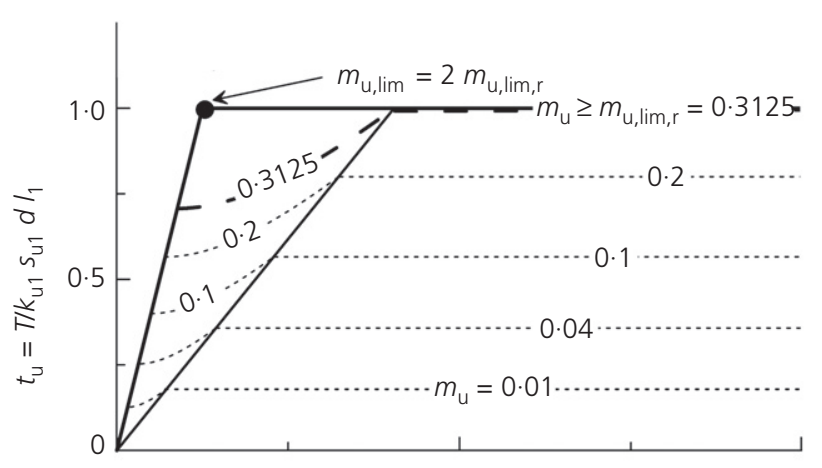

(a)

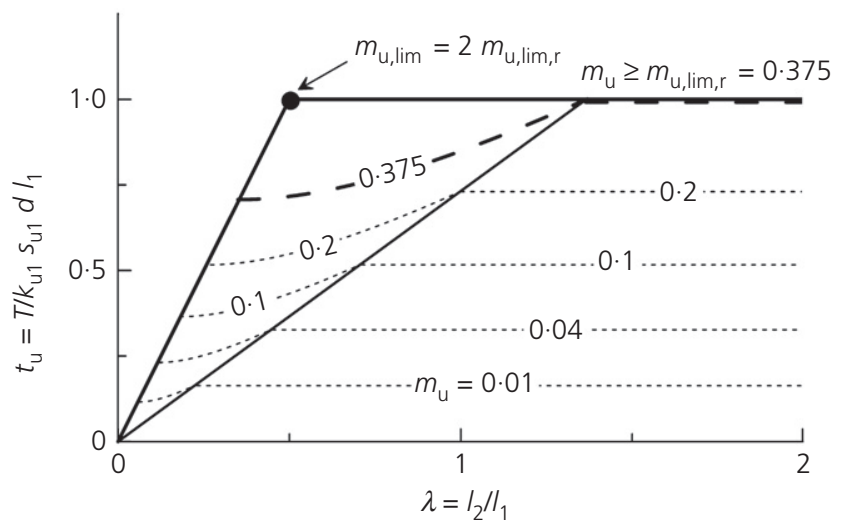

(b)

Fig. 6. Dimensionless shear force for fixed-head piles in undrained conditions for different values of dimensionless yielding moment and strength ratio of sliding and firm soil: (a) $\chi_{\mathrm{u}}=0.25$; (b) $\chi_{u}=0.5$

cohesion and friction angle) and groundwater level at an arbitrary location, yet this is not done here due to space limitations.

Figure 7 is a sketch of the failure mechanisms with associated patterns of soil reaction and internal forces along the pile. From equilibrium considerations, as already shown by Muraro et al. (2014) dimensionless shear force and bending moment at the interface for mechanisms $\mathrm{A}$ and $\mathrm{C}$ are obtained as

Mode A

$$
t_{\mathrm{dA}}=\frac{T_{\mathrm{A}}}{k_{\mathrm{d} 1} \gamma d l_{1}^{2}}=\frac{\lambda}{\chi_{\mathrm{d}}}\left(\frac{\lambda}{2}+1\right)
$$




$$
\frac{M_{\mathrm{A}}}{k_{\mathrm{d} 1} \gamma d l_{1}^{3}}=-\frac{\lambda^{2}}{\chi_{\mathrm{d}}}\left(\frac{1}{2}+\frac{1}{3} \lambda\right)
$$

Mode C

$$
\begin{gathered}
t_{\mathrm{dC}}=\frac{T_{\mathrm{C}}}{k_{\mathrm{d} 1} \gamma d l_{1}^{2}}=\frac{1}{2} \\
\frac{M_{\mathrm{C}}}{k_{\mathrm{d} 1} \gamma d l_{1}^{3}}=\frac{1}{6}
\end{gathered}
$$

where $\gamma$ is the unit weight of the soil, taken for simplicity as identical for the two layers, $k_{\mathrm{d} 1}=3 k_{\mathrm{p} 1}$ (following Broms, 1964b) and $\chi_{\mathrm{d}}=k_{\mathrm{p} 1} / k_{\mathrm{p} 2}$.

To take into account the inclination of slope $\alpha$, Rankine's passive earth pressure coefficients $k_{\mathrm{p} 1}$ and $k_{\mathrm{p} 2}$ must be evaluated through the classical expressions for infinite slope.

For mechanism B, the expressions for dimensionless shear force cannot be derived in closed form. Thus, the problem is tackled numerically, solving for each set of $\lambda$ and $\chi_{\mathrm{d}}$ values the two equilibrium equations iteratively. The solutions were obtained by means of Matlab software for both cases of infinite and finite values of cross-sectional dimensionless yielding moment (modes B1, BY and B2), defined as

$$
m_{\mathrm{d}}=\frac{M_{\mathrm{y}}}{k_{\mathrm{d} 1} \gamma d l_{1}^{3}}
$$

Note that parameters $m_{\mathrm{d}}^{*}, m_{\mathrm{d}, \lim }$ and $m_{\mathrm{d}, \mathrm{lim}, \mathrm{r}}$ have the same meaning as $m_{\mathrm{u}}^{*}, m_{\mathrm{u}, \lim }$ and $m_{\mathrm{u}, \mathrm{lim}, \mathrm{r}}$, yet they are indicated with different symbols due to the different normalisations. The ultimate shear force and moment offered by the pile is represented in Fig. 8 for different values of strength ratios and dimensionless yielding moment. For restrained-head piles, the same trends are observed as for the undrained case and the quantitative results are depicted in Fig. 9.

Limit values of embedment ratio and dimensionless bending moment can be obtained by interpolating the numerical results. Regression formulae for critical embedment ratio and dimensionless bending for both freeand fixed-head piles in drained conditions, depicted in Fig. 10, are

$$
\begin{aligned}
& \lambda_{\lim }=1.192 \cdot \chi_{\mathrm{d}}^{0.61} \\
& m_{\mathrm{d}, \lim }=0.108 \cdot \chi_{\mathrm{d}}+0.17 \\
& \lambda_{\lim , \mathrm{r}}=0.977 \cdot \chi_{\mathrm{d}}^{0.64} \\
& m_{\mathrm{d}, \mathrm{lim}, \mathrm{r}}=0.053 \cdot \chi_{\mathrm{d}}+0.086
\end{aligned}
$$

It is noted that, as in the undrained case, the dimensionless limit moment for a restrained pile is one-half of that associated to the free-head pile.
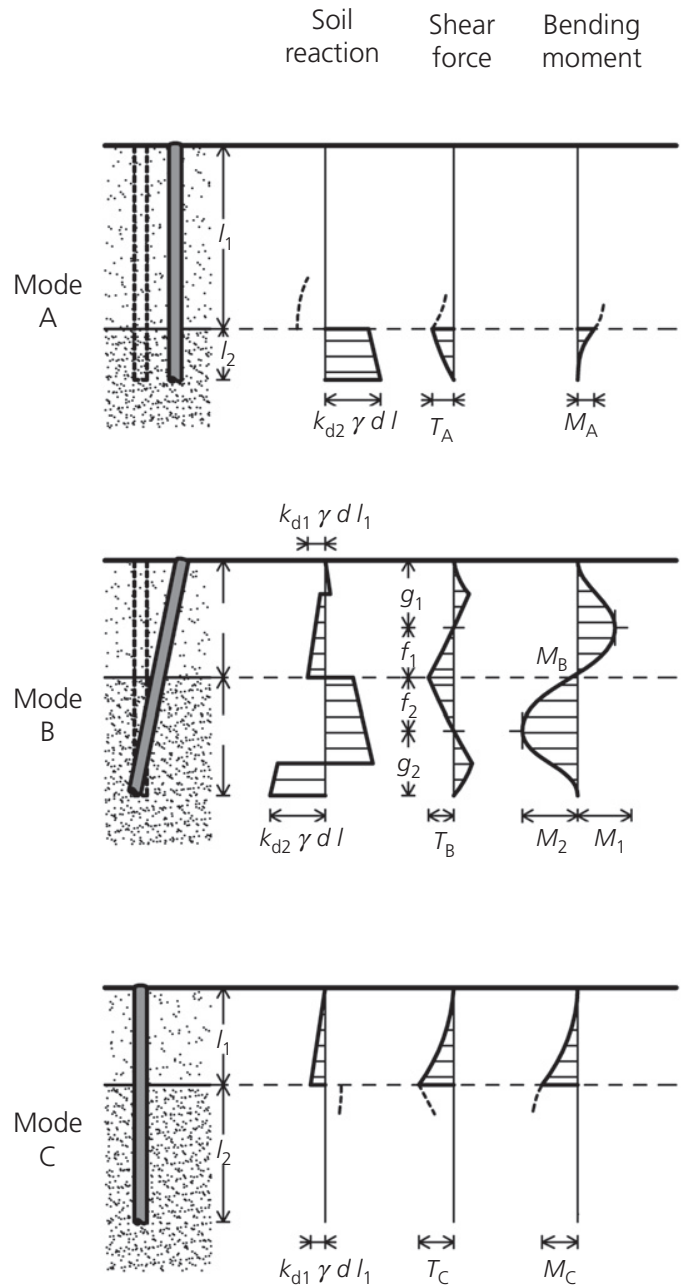

reaction

Shear

force

Bending

moment
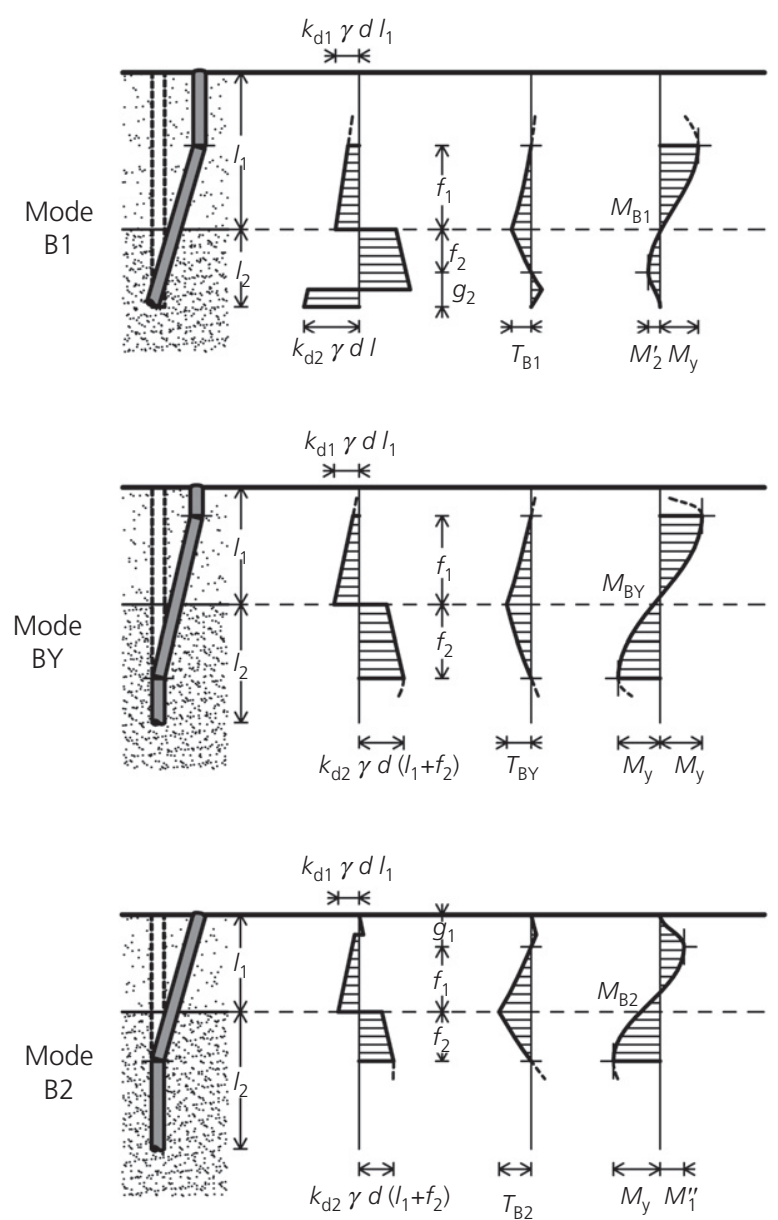

Fig. 7. Failure mechanisms and associated distribution of soil reaction, shear force and bending moment in drained conditions 


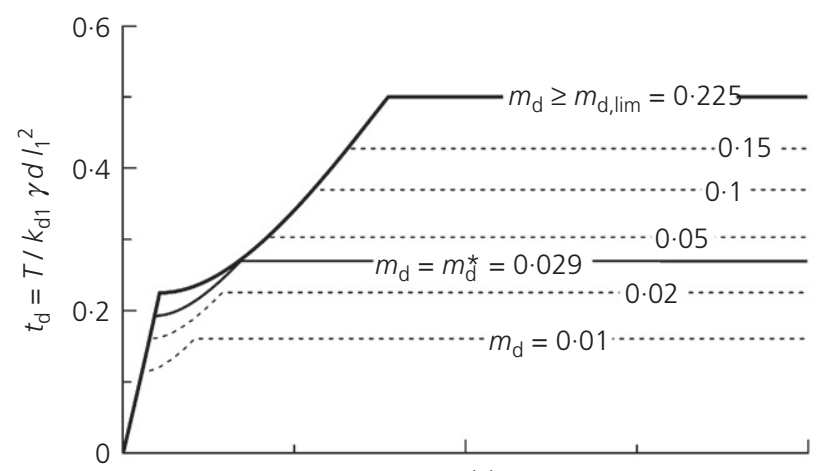

(a)

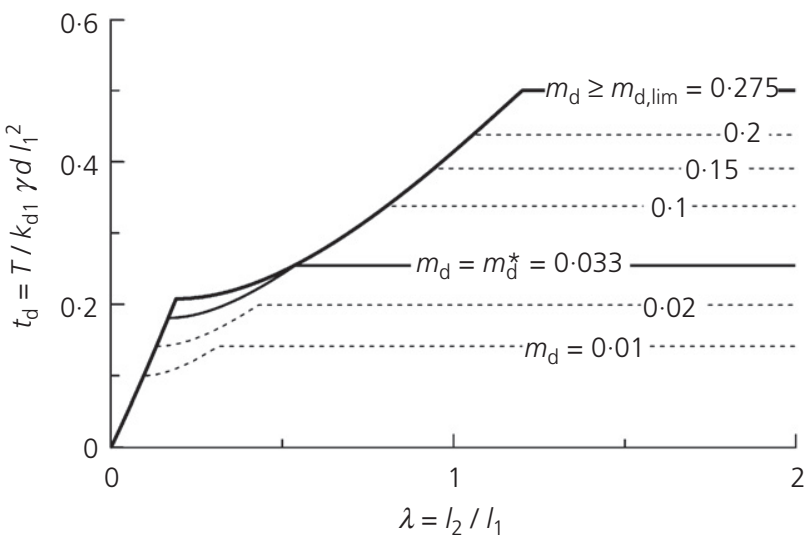

(b)
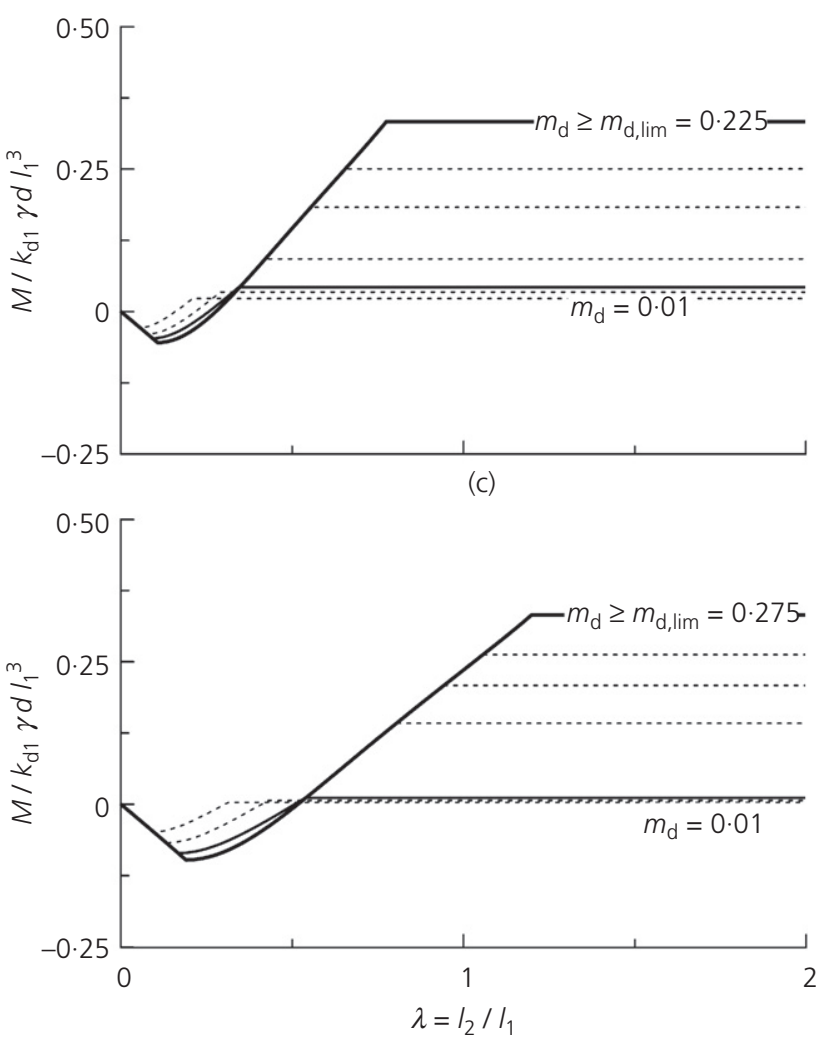

(d)

Fig. 8. Dimensionless shear force and moment for free-head piles in drained conditions for different values of dimensionless yielding moment and strength ratio of sliding and firm soil: (a) $\chi_{\mathrm{d}}=0.5$; (b) $\chi_{\mathrm{d}}=1$; (c) $\chi_{\mathrm{d}}=0.5$; (d) $\chi_{\mathrm{d}}=1$

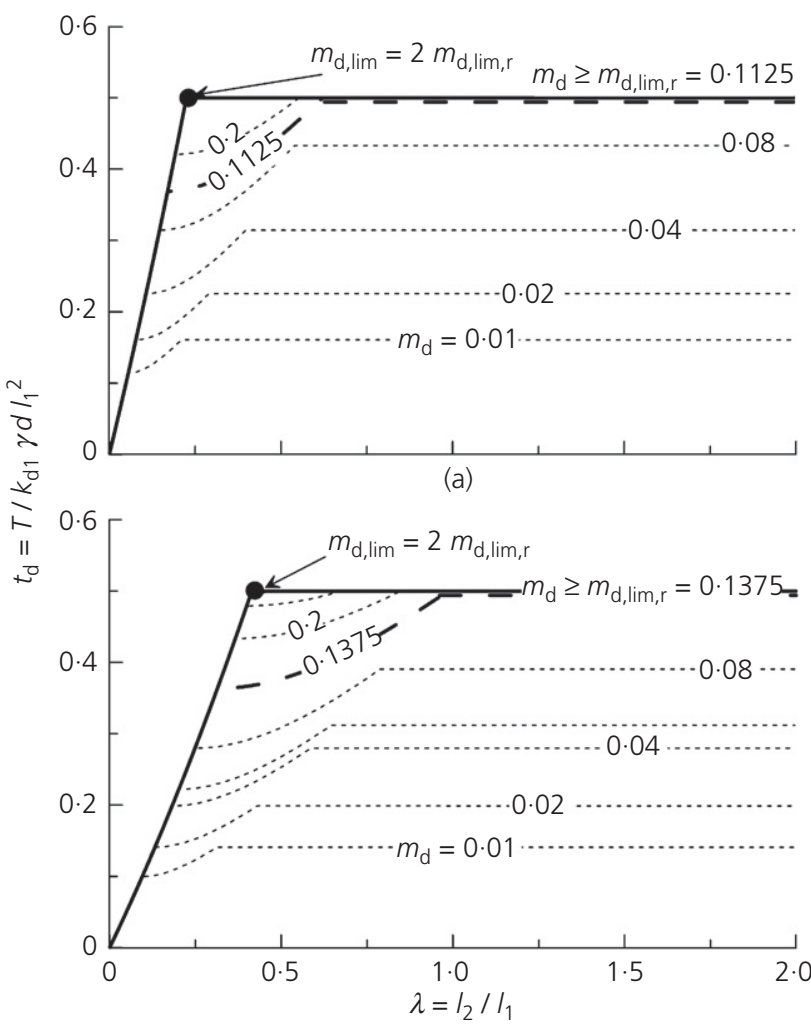

(b)

Fig. 9. Dimensionless shear force for fixed-head piles in drained conditions for different values of dimensionless yielding moment and strength ratio of sliding and firm soil: (a) $\chi_{d}=0 \cdot 5$; (b) $\chi_{\mathrm{d}}=1$

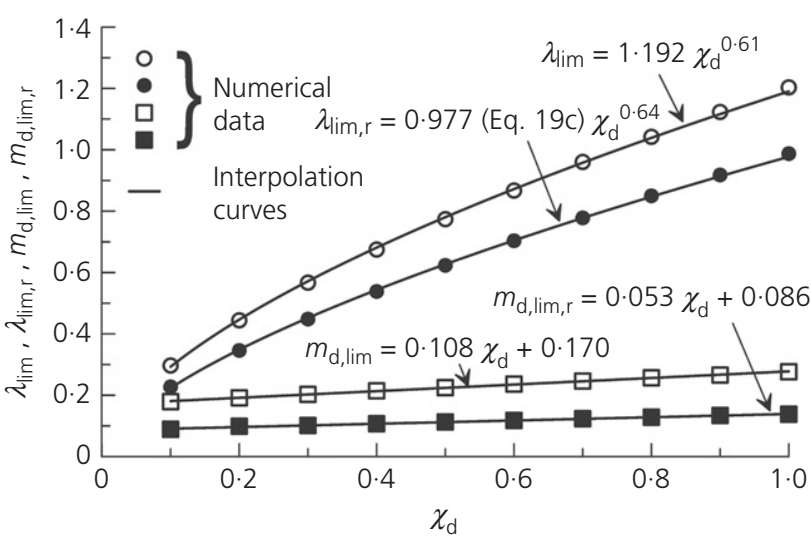

Fig. 10. Regression formulae for critical embedment ratio and dimensionless bending for both free- and fixed-head piles in drained conditions

\section{CONCLUSIONS}

In this paper, several formulae have been provided for the ultimate load of slope-stabilising piles, to be used in routine limit equilibrium slope-stability analyses. Pile contribution may be expressed through a force and a moment, derived in this work for free- and fixed-head piles, in drained and undrained conditions, for infinite and finite pile section flexural capacity. Analytical solutions have been derived for all failure mechanisms in the undrained case (total stress analysis). For the drained case, analytical solutions are provided whenever their derivation is possible, while closedform approximate expressions, which fit well the numerical data, are reported for the other mechanisms. 


\section{ACKNOWLEDGEMENTS}

This research was supported by the National Relevant Interest Research Program (PRIN 2010-2011). The authors express their gratitude to those responsible for the research project, Professor Leonardo Cascini of the University of Salerno.

\section{REFERENCES}

Ausilio, E., Conte, E. \& Dente, G. (2001). Stability analysis of slopes reinforced with piles. Comput. Geotech. 28, No. 8, 591-611.

Baguelin, F., Frank, R. \& Said, Y. H. (1977). Theoretical study of lateral reaction mechanism of piles. Géotechnique 27, No. 3 , 405-434, http://dx.doi.org/10.1680/geot.1977.27.3.405.

Broms, B. (1964a). Lateral resistance of piles in cohesive soils. J. Soil Mech. Found. Div. 90, No. SM2, 27-64.

Broms, B. (1964b). Lateral resistance of piles in cohesionless soils. J. Soil Mech. Found. Div. 90, No. SM3, 123-156.

Cai, F. \& Ugai, K. (2000). Numerical analysis of the stability of a slope reinforced with piles. Soils Found. 40, No. 1, 73-84.

Chmoulian, A. (2004). Briefing: analysis of piled stabilization of landslides. Proc. Instn Civil Engrs - Geotech. Engng 157, No. 2, 55-56, http://dx.doi.org/10.1680/geng.2004.157.2.55.

De Beer, E. E. \& Carpentier, R. (1977). Discussion of the paper by Ito and Matsui (1975). Soils Found. 16, No. 1, 68-82.

Fukuoka, M. (1977). The effects of horizontal loads on piles due to landslides. Proceedings of the 9 th international conference on soil mechanics and foundation engineering, Tokyo, Japan, pp. 27-42. Tokyo, Japan: Japanese Society of Soil Mechanics and Foundation Engineering.

Guo, W. D. (2006). On limiting force profile, slip depth and lateral pile response. Comput. Geotech. 33, No. 1, 47-67.

Hassiotis, S., Chameau, J. L. \& Gunaratne, M. (1997). Design method for stabilization of slopes with piles. J. Geotech Geoenviron. Engng ASCE 123, No. 4, 314-323.

Hull, T. S. (1993). Analysis of the stability of slopes with piles. In Proceeding of 11th Southeast Asian Geotechnical Conference, Singapore, pp. 639-643. Pathumthani, Thailand: Southeast Asian Geotechnical Society.

Ito, T. \& Matsui, T. (1975). Methods to estimate lateral force acting on stabilizing piles. Soils Found. 15, No. 4, 43-59.

Ito, T., Matsui, T. \& Hong, W. P. (1979). Design method for the stability analysis of the slope with landing pier. Soils Found. 19, No. 4, 21-33
Kourkoulis, R., Gelagoti, F., Anastasopoulos, I. \& Gazetas, G. (2011). Slope stabilizing piles and pile-groups: parametric study and design insights. J. Geotech. Geoenviron. Engng ASCE 137, No. 7, 663-678.

Kourkoulis, R., Gelagoti, F., Anastasopoulos, I. \& Gazetas, G. (2012). Hybrid method for analysis and design of slope stabilizing piles. J. Geotech. Geoenviron. Engng ASCE 138, No. $1,1-14$

Lee, C. Y., Hull, T. S. \& Poulos, H. G. (1995). Simplified pile-slope stability analysis. Comput. Geotech. 17, No. 1, 1-16.

Muraro, S., Madaschi, A. \& Gajo, A. (2014). On the reliability of $3 \mathrm{D}$ numerical analyses on passive piles used for slope stabilisation in frictional soils. Géotechnique 64, No. 6, 486-492, http://dx.doi.org/10.1680/geot.13.T.016.

Oakland, M. W. \& Chameau, J. L. A. (1984). Finite element analysis of drilled piers used for slope stabilization. In Laterally loaded deep foundations: analysis and performance (eds J. A. Langer, E. T. Mosley and C. D. Thompson), ASTM STP 835, pp. 182-193. West Conshohocken, PA, USA: ASTM.

Pan, D., Smethurst, J. A. \& Powrie, W. (2012). Limiting pressure on a laterally loaded pile in a frictional soil. Géotech. Lett. 2, No. 2, 55-60, http://dx.doi.org/10.1680/geolett.12.00007.

Poulos, H. G. (1973). Analysis of piles in soil undergoing lateral movement. J. Soil Mech. Found. Div. 99, No. SM5, $391-406$.

Poulos, H. G. (1995). Design of reinforcing piles to increase slope stability. Can. Geotech. J. 32, No. 5, 808-818.

Poulos, H. G. (1999). Design of slope stabilizing piles. In Slope stability engineering (eds J. C. Jiang, N. Yagu and T. Yamagami), pp. 397-405. Rotterdam, the Netherlands: Balkema.

Poulos, H. G. \& Chen, L. T. (1997). Pile response due to excavationfinduced lateral soil movement. J. Geotech. Geoenviron. Engng $A S C E$ 123, No. 2, 94-99.

Smethurst, J. A. \& Powrie, W. (2007). Monitoring and analysis of the bending behaviour of discrete piles used to stabilise a railway embankment. Géotechnique 57, No. 8, 663-677, http://dx.doi.org/10.1680/geot.2007.57.8.663.

Sommer, H. (1977). Creeping slope in a stiff clay. Proceedings of the 9 th international conference on soil mechanics and foundation engineering, Tokyo, Japan, pp. 113-118. Tokyo, Japan: Japanese Society of Soil Mechanics and Foundation Engineering.

Viggiani, C. (1981). Ultimate lateral load on piles used to stabilize landslides. Proceedings of the 10th international conference on soil mechanics and foundation engineering, Stockholm, Sweden, vol. 3, pp. 555-560. Rotterdam, the Netherlands: Balkema. 